Pacific Journal of Mathematics

CONDITIONS FOR COUNTABLE BASES IN SPACES OF 


\title{
CONDITIONS FOR COUNTABLE BASE IN SPACES OF COUNTABLE AND POINT-COUNTABLE TYPE
}

\author{
Michael HenRy
}

A space $X$ is of countable type if for every compact $C \subset X$, there exists a compact set $K$ having a countable basis with $C \subset K . \quad X$ is of point-countable type if there exists a covering of compact subsets of $X$, each having a countable basis. It is shown that in a Hausdorff space of countable type, a compact set has a countable basis if and only if it is a $G_{\delta}$-set. Similarly, for Hausdorff spaces of point-countable type, a point has a countable basis if and only if it is a $G_{\hat{o}}$-set.

1. Terminology. Notation and terminology will follow that of Dugundji [2]. By a neighborhood of a set $A$, we will mean an open set containing $A$.

If $X$ is a space and $A \subset X$, a collection $\mathscr{D}$ of neighborhoods of $A$ is called a basis at $A$ if and only if for every neighborhood 0 of $A$, there exists $D \in \mathscr{D}$ with $A \subset D \subset 0$.

If $X$ is a space and $A \subset X$, then $A$ is said to be of countable character if and only if there exists a countable basis at $A$.

A space $X$ is said to be of countable type if for every compact $C \subset X$, there exists a compact set $K$ of countable character with $C \subset K$.

A space $X$ is said to be of point-countable type if there exists a covering of compact subsets of $X$, each having countable character.

2. Discussion and theorems. Every first countable space, as well as every locally compact Hausdorff space, is of point-countable type, while spaces of point-countable type are, in turn, $k$-spaces. Compact spaces are trivially of countable type, but these two concepts are fairly far removed from each other since a metric space is of countable type.

The following lemmas will be needed. Lemma 2, which was first noted by Arhangel'skiî [1], can be verified by a slight modification of Wicke's proof of Lemma 1. The author is indebted to Howard Cook for some valuable suggestions.

Lemma 1. (Wicke). In a Hausdorff space $X$, the following properties are equivalent:

(i) $X$ is of point-countable type.

(ii) If 0 is an open set in $X$ and $x \in 0$, there exists a compact set $B$ of countable character such that $x \in B$ and $B \subset 0$.

Lemma 2. (Arhangel'skii). Suppose $X$ is a Hausdorff space of 
countable type, $U$ is an arbitrary compact subset, and 0 is any of its neighborhoods. Then there exists a compact set $C$ of countable character such that $U \subset C \subset 0$.

Lemma 3. Let $X$ be a Hausdorff space and let $U$ and $V$ be compact subsets of countable character. Then $U \cap V$ is also a compact set of countable character.

Proof. That $U \cap V$ is compact is obvious. Denote the members of the countable bases at $U$ and $V$ by $U_{n}$ and $V_{n}$, respectively, and assume that the collections $\left\{U_{n}\right\}$ and $\left\{V_{n}\right\}$ are descending. It will be shown that the collection $\left\{U_{n} \cap V_{n}\right\}$ forms a local basis at $U \cap V$. Thus, let 0 be any neighborhood of $U \cap V$. Then $U-0$ and $V-0$ are disjoint compact sets, and hence there exist disjoint open sets $U^{*}$ and $V^{*}$ with $U-0 \subset U^{*}$ and $V-0 \subset V^{*}$. Since $U^{*} \cup 0$ is a neighborhood of $U$, there exists an integer $m$ with $U \subset U_{m} \subset U^{*} \cup 0$. Similarly, there exists an integer $n$ with $V \subset V_{n} \subset V^{*} \cup 0$. Letting $k=\max \{m, n\}$, it follows that $U \cap V \subset U_{k} \cap V_{k} \subset 0$; for if this is not true then there must exist a point $p \in U_{k} \cap V_{k}-0$ which implies that $p \in U^{*} \cap V^{*}$, contradicting the disjointness of $U^{*}$ and $V^{*}$.

For $n \geqq 1$, it follows from Lemma 2 that there exists a compact set $C_{n}^{\prime}$ of countable character such that $U \subset C_{n}^{\prime} \subset G_{n}$. Let $C_{n}=\bigcap_{\imath=1}^{n} C_{\imath}^{\prime}$. By Lemma 3, each $C_{n}$ is also a compact set of countable character.

THeOREM 1. Let $X$ be a Hausdorff space of countable type and let $U$ be any compact subset which is also a $G_{\delta}$-set. Then $U$ has a countable basis.

Proof. By hypothesis, there exist neighborhoods $G_{n}$ of $U$ such that $U=\bigcap_{n=1}^{\infty} G_{n}$. Construct a sequence $\left\{C_{n}\right\}$ of compact sets in the following manner:

By Lemma 2, there exists a compact set $C_{1}$ of countable character such that $U \subset C_{1} \subset G_{1}$. For $n>1$, it also follows from Lemma 2 that there exists a compact set $C_{n}^{\prime}$ of countable character such that $U \subset$ $C_{n}^{\prime} \subset G_{n}$. Let $C_{n}=\left[\bigcap_{i=1}^{n-1} C_{i}\right] \cap C_{n}^{\prime}$. From a previous remark, each $C_{n}$ is also a compact set of countable character.

Let $\left\{U_{m, n}\right\}$ be a countable basis at $C_{m}$. Clearly, $U \subset U_{m, n}$ for every pair $(m, n)$, and furthermore, $U \subset \bigcap_{m, n} U_{m, n} \subset \bigcap_{n=1}^{\infty} G_{n}=U$. Hence, $\bigcap_{m, n} U_{m, n}=U$. It will now be shown that the collection $\left\{U_{m, n}\right\}$ is a basis at $U$. Indeed, if it is not, then there exists a neighborhood $K$ of $U$ such that $U_{m, n}-K \neq \phi$ for every pair $(m, n)$. This forces $C_{m}-K \neq \phi$ for each integer $m$ because, if not, then $C_{m} \subset K$ for some $m$, and hence there exists an integer $n$ with $C_{m} \subset U_{m, n} \subset K$ which is contrary to our assumption. Since $C_{m}-K$ is a decreasing sequence of 
nonempty compact sets, $\bigcap_{m=1}^{\infty}\left[C_{m}-K\right] \neq \phi$. But if $p \in \bigcap_{m=1}^{\infty}\left[C_{m}-K\right]$, then $p \in \bigcap_{m, n} U_{m, n}$ which implies that $p \in U$. This is impossible since $p \in X-K$ and $U \subset K$. Thus, $\left\{U_{m, n}\right\}$ is a basis at $U$, and the theorem is proved.

COROLlary. In a Hausdorff space of countable type, a compact set has a countable basis if and only if it is a $G_{\delta}$-set.

THEOREM 2. Let $X$ be a Hausdorff space of point-countable type, and let $p \in X$ be any point which is a $G_{\delta}$-set. Then $p$ has a countable basis.

Proof. In the proof of Theorem 1, use Lemma 1 instead of Lemma 2 and substitute "point $p$ " in place of $U$.

CoRollary. A Hausdorff space is first countable if and only if it is of point countable type and each point is a $G_{\delta}$-set.

COROLlary. A locally compact Hausdorff space is first countable if and only if each point is a $G_{\delta}$-set.

\section{REFERENCES}

1. A. V. Arhangel'skii, On a class of spaces containing all metric and all locally bicompact spaces, Soviet Math. Dokl. 4 (1963), 1051-1055.

2. James Dugundji, Topology, Allyn and Bacon, Boston, Mass., 1966.

3. H. H. Wicke, On the Hausdorff open continuous images of Hausdorff paracompact p-spaces, Proc. Amer. Math. Soc. 22 (1969), 136-140.

Received May 4, 1970, and in revised form June 26, 1970. This research was supported by a TCU Research Fellowship and represents a portion of the author's doctoral dissertation, which was begun under the direction of the late Professor H. Tamano and completed under D. R. Traylor and Howard Cook.

TeXas Christian University 



\title{
PACIFIC JOURNAL OF MATHEMATICS
}

\author{
EDITORS
}

H. SAMELSON

Stanford University

Stanford, California 94305

C. R. Новву

University of Washington

Seattle, Washington 98105
J. DUGUNDJI

Department of Mathematics

University of Southern California

Los Angeles, California 90007

RICHARD ARENS

University of California

Los Angeles, California 90024

\section{ASSOCIATE EDITORS}

E. F. BECKENBACH

B. H. NeUManN

F. WOLF

K. YosHidA

\section{SUPPORTING INSTITUTIONS}

UNIVERSITY OF BRITISH COLUMBIA CALIFORNIA INSTITUTE OF TECHNOLOGY UNIVERSITY OF CALIFORNIA MONTANA STATE UNIVERSITY UNIVERSITY OF NEVADA NEW MEXICO STATE UNIVERSITY OREGON STATE UNIVERSITY UNIVERSITY OF OREGON OSAKA UNIVERSITY UNIVERSITY OF SOUTHERN CALIFORNIA
STANFORD UNIVERSITY UNIVERSITY OF TOKYO UNIVERSITY OF UTAH WASHINGTON STATE UNIVERSITY UNIVERSITY OF WASHINGTON

AMERICAN MATHEMATICAL SOCIETY CHEVRON RESEARCH CORPORATION TRW SYSTEMS

NAVAL WEAPONS CENTER 


\section{Pacific Journal of Mathematics}

\section{Vol. 36, No. $1 \quad$ November, 1971}

Norman Larrabee Alling, Analytic and harmonic obstruction on

nonorientable Klein surfaces ............................ 1

Shimshon A. Amitsur, Embeddings in matrix rings .............. 21

William Louis Armacost, The Frobenius reciprocity theorem and essentially bounded induced representations ....................... 31

Kenneth Paul Baclawski and Kenneth Kapp, Topisms and induced

non-associative systems ............................ 45

George M. Bergman, The index of a group in a semigroup ............ 55

Simeon M. Berman, Excursions above high levels for stationary Gaussian

processes....................................... 63

Peter Southcott Bullen, A criterion for $n$-convexity .............. 81

W. Homer Carlisle, III, Residual finiteness of finitely generated commutative

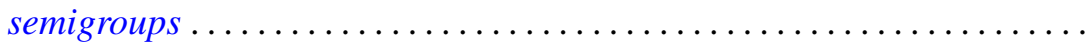

Roger Clement Crocker, On the sum of a prime and of two powers of

two ............................................ 103

David Eisenbud and Phillip Alan Griffith, The structure of serial rings . . . 109

Timothy V. Fossum, Characters and orthogonality in Frobenius

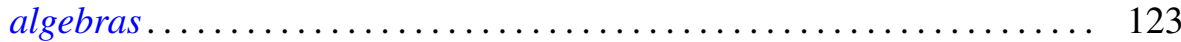

Hugh Gordon, Rings of functions determined by zero-sets . .......... 133

William Ray Hare, Jr. and John Willis Kenelly, Characterizations of Radon partitions...

Philip Hartman, On third order, nonlinear, singular boundary value

problems

David Michael Henry, Conditions for countable bases in spaces of

countable and point-countable type ..

James R. Holub, Hilbertian operators and reflexive tensor products ...

Robert P. Kaufman, Lacunary series and probability ..... . .

195

Erwin Kreyszig, On Bergman operators for partial differential equations in

two variables ................................

Chin-pi Lu, Local rings with noetherian filtrations . .

Louis Edward Narens, A nonstandard proof of the Jordan curve theorem...

S. P. Philipp, Victor Lenard Shapiro and William Hall Sills, The Abel summability of conjugate multiple Fourier-Stieltjes integrals. .

Joseph Earl Valentine and Stanley G. Wayment, Wilson angles in linear normed spaces

Hoyt D. Warner, Finite primes in simple algebras ...

Horst Günter Zimmer, An elementary proof of the Riemann hypothesis for an elliptic curve over a finite field... 